\title{
Replacement of Missing Lateral Incisor Using A Zirconium Resin-Bonded Fixed Partial Denture: A Clinical Report
}

\author{
Kammoun $\mathrm{R}^{* 1}$, Hadyaoui $\mathrm{D}^{2}$, Ghoul Mazgar $\mathrm{S}^{1}$, Saafi $\mathrm{J}^{2}$, Harzallah $\mathrm{H}^{2}$, Troudi $\mathrm{F}^{2}$ and Cherif $\mathrm{M}^{2}$ \\ ${ }^{1}$ Department of Histology-Embryology, Faculty of Dental Medicine Monastir, University of Monastir, Tunisia \\ ${ }^{2}$ Department of Prosthetic Dentistry, Faculty of Dental Medicine Monastir, University of Monastir, Tunisia
}

${ }^{*}$ Corresponding author: Kammoun R, Department of Histology-Embryology, Faculty of Dental Medicine Monastir University of Monastir, Tunisia, Tel: +216 22751787, E-mail: rym1kammoun@gmail.com

Citation: Kammoun R, Hadyaoui D, Ghoul Mazgar S, Saafi J, Harzallah H, et al. (2016) Replacement of Missing Lateral Incisor Using A Zirconium Resin-Bonded Fixed Partial Denture: A Clinical Report. J Dent Oral Care Med 2(2): 202. doi: 10.15744/2454-3276.2.202

Received Date: February 04, 2016 Accepted Date: May 09, 2016 Published Date: May 10, 2016

\begin{abstract}
This clinical report describes the treatment of a 22 -year-old female patient with maxillary lateral incisor agenesis. All-ceramic resinbonded fixed partial dentures (RBFPD) were selected as the most conservative and esthetic treatment option. Zirconia-based RBFPDs were fabricated and adhesively bonded to the abutment teeth, closely following the protocols suggested by the most recent scientific evidence. No clinical complications were observed at the follow-up examination after placement of the $\mathrm{ZrO}_{2}$ ceramic $\mathrm{RBFPD}$, and satisfactory functional and esthetic results were achieved.
\end{abstract}

Keywords: Zirconium Oxide; Dental Bonding; Denture; Partial; Fixed; Resin-Bonded; Ceramics

\section{Introduction}

In today's dental practice a missing tooth in the anterior region of mouth is not only a physical loss, but also an emotional experience for the patient as well. Missing lateral incisors is one of the most common congenital dental anomalies. New technology and materials offer a wide variety of treatment options for the replacement of missing teeth in order to improve esthetics and restore functions. So, there are several options that exist for replacing it. These include an implant-supported prosthesis, a conventional fixed dental prosthesis (FDP), and a resin-bonded fixed partial denture (RBFPD). The treatment of choice should be the least invasive option that satisfies the expected esthetic and functional objectives [1]. An implant-supported prosthesis has become a common method of replacing a missing tooth. However, there are still certain instances in which implants cannot be used. For example, when available bone volume is minimal, or when the adjacent root is in close proximity. Other circumstances also may prohibit the use of implants, including young age (incomplete growth), severe occlusal discrepancies and financial contraints [2]. In these situations, a tooth-supported prosthesis must be considered. Unfortunately, the conventional FDP is the least conservative option, the invasive nature of the treatment can lead to other complications throughout the life of the restoration. Complications may include mechanical overload of the abutment teeth with weakening or fracture, risk of endodontic treatment, periodontal problems, decay, and cement failure. If any of these complications occurs on one of the abutment teeth, the entire prosthesis will fail [3].

A resin-bonded fixed partial denture (RBFPD) represents a very conservative treatment approach. Clinical indications for conventional RBFPDs include vital and intact abutment teeth, a short edentulous span such as 1 or 2 missing teeth, and minimal dynamic occlusal contacts on the abutment teeth. Various studies on this issue have been done and published, proving that RBFPDs have shown successful results after a 10 and 13-year follow-up periods [4,5]. Furthermore, study performed by Pjetursson, et al. showed that RBFPDs offer an acceptable survival rate which has been evaluated between $81.6 \%$ and $91.9 \%$ after 5 years [6]. Despite the scientific acceptance of anterior RBFPDs, many practitioners may have reservations about this option because they are afraid from clinical failures that are mainly associated with debonding of the framework from the abutment teeth and wing frature. Studies indicate that improvements in adhesive technology along with adapted preparation designs have the ability to limit bonding failures and significantly increase the clinical longevity of RBFPDs [5]. 
Traditional RBFPDs made with a metal framework have one esthetic disadvantage a grayish discoloration of the abutment teeth caused by a shadow effect of the framework showing through the tooth enamel. All-ceramic RBFPDs with a white or tooth-colored framework can minimize this disadvantage. Zirconia-oxide ceramic not only can resolve this esthetic problem but is also a very resistant and durable material due to its fracture strength that can exceed $1000 \mathrm{MPa}$ [7]. In fact, this material improves the rigidity of all ceramic RBFPDs and allows them to reduce the distortion under functional loads. Zirconia-oxide ceramic is characterized also by the ability to be milled in fine details, a very good biocompatibility and esthetic results $[8,9]$.

This clinical report describes an alternative treatment for the replacement of a congenitally missing lateral incisor using a zirconium resin-bonded fixed partial denture (ZRBFPD).

\section{Case report}

A 22-year-old female patient with a noncontributory medical history presented to the Fixed Prosthetics Department of the Dentistry Clinic, University of Monastir for the replacement of the upper left lateral incisor, after the extraction of primary upper left lateral incisor mobile and much abraded. Extra oral examination revealed symmetrical face, straight to convex profile and a normal facial musculature. Intra oral examination showed that the mandibular canine in the left side was in buccal position, this helped reducing involved surfaces in dynamic occlusion in favor of a shallow bite. Occlusion evaluation showed canine guidance. Radiographic analysis was conducted to confirm the agenesis and to ensure that the designated abutments had adequate periodontal health and root support. Abutment teeth were vital, immobile and free from caries (Figure 1).

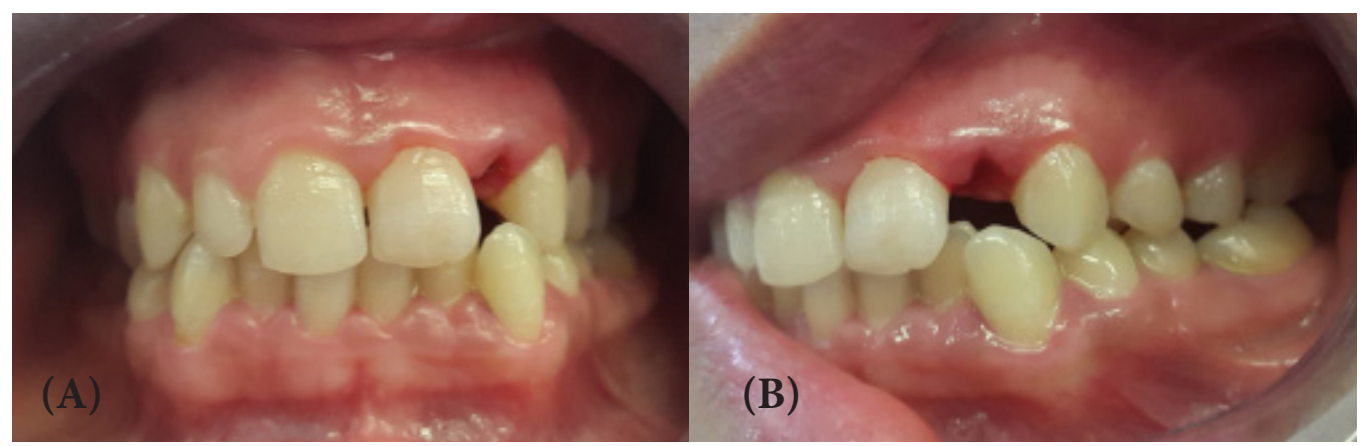

Figure 1: Preoperative view of the patient after extraction of the primary upper left lateral incisor. A: frontal view, B: lateral view

An Implant-supported crown, a RBFPD, or a conventional FPD, were the treatment options presented to the patient for the replacement of her missing tooth. However, radiographic findings revealed unfavorable root proximity which did not allow implant placement in the site of the missing lateral. Although, conventional FPD was not the most suitable solution for the patient and it was also excluded because the abutment teeth were vital and intact. However, based on conservative considerations, length of treatment and cost, RBFPD was the suitable solution. A diagnostic wax up was performed which revealed enough occlusal clearance without any tooth preparation. Occlusion was examined with a piece of articulating paper, the impact point was identified and the limits of preparation were localized just behind these impacts. Central incisor and canine were reduced with flame-shaped, chamfer, and shoulder diamond rotary cutting instruments to shape the adequate profile suitable for mechanical behavior of ceramis. The palatal surfaces of the abutment teeth were reduced by about $0.6 \mathrm{~mm}$, with a supra-gingival chamfer finish line about $1 \mathrm{~mm}$ from the tissue crest and $2 \mathrm{~mm}$ from occlusal reduction (Figure 2).

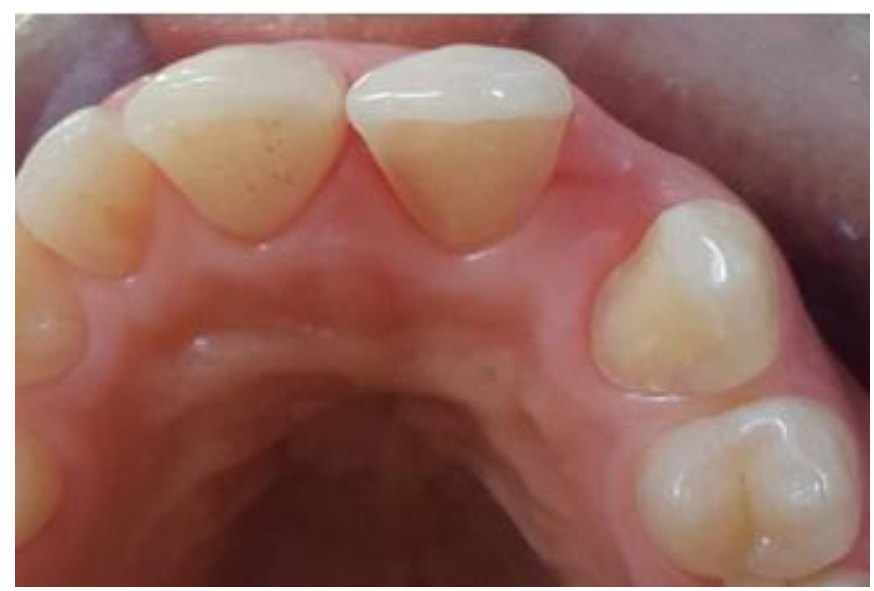

Figure 2: Occlusal view of prepared abutments 
The finish line continued in proximal, while remaining just behind distal contact point to avoid undercuts. Proximal extensions of preparation provide increased tooth surface available for bonding and increase framework connector strength. The preparation was carefully polished to avoid any risk of ceramic fracture. In fact, the prepared area consisting the future bonding zone does not offer mechanical retention but only the seating of the restoration.

A complete arch impression was made with a silicone impression material (Figure 3), then was transferred to the laboratory to be casted. The master cast was checked and the limits of the prepared surfaces were marked (Figure 4). Master casts and opposing casts were mounted, on an articulator. Then, models were referred to the technician to be scanned. Provisional restorations were made by placing an auto-polymerizing resin directly on prepared unetched tooth surfaces, finished, and polished (Figure 5). A framework of the all-ceramic RBFPD was fabricated using $\mathrm{ZrO}_{2}$ ceramic manufactured by a CAD-CAM system.

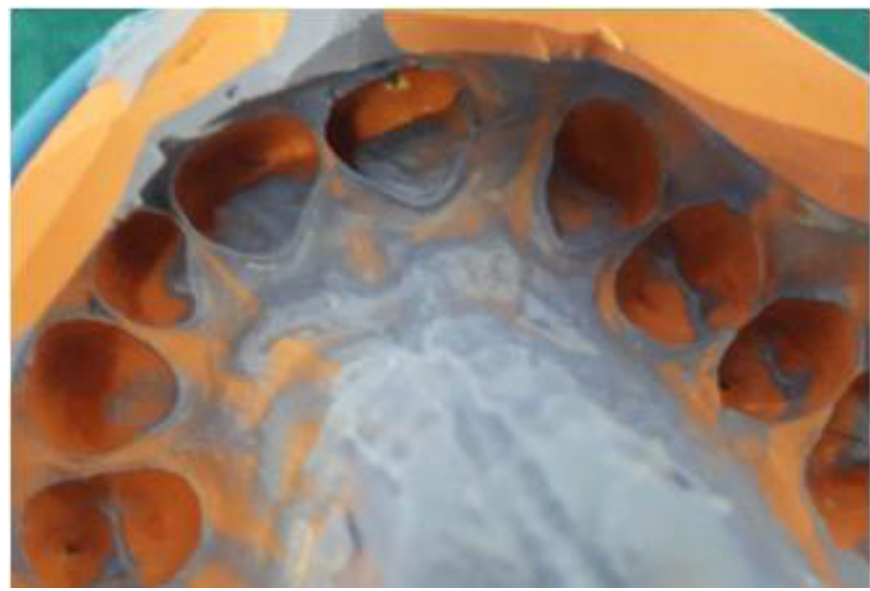

Figure 3: Final impression

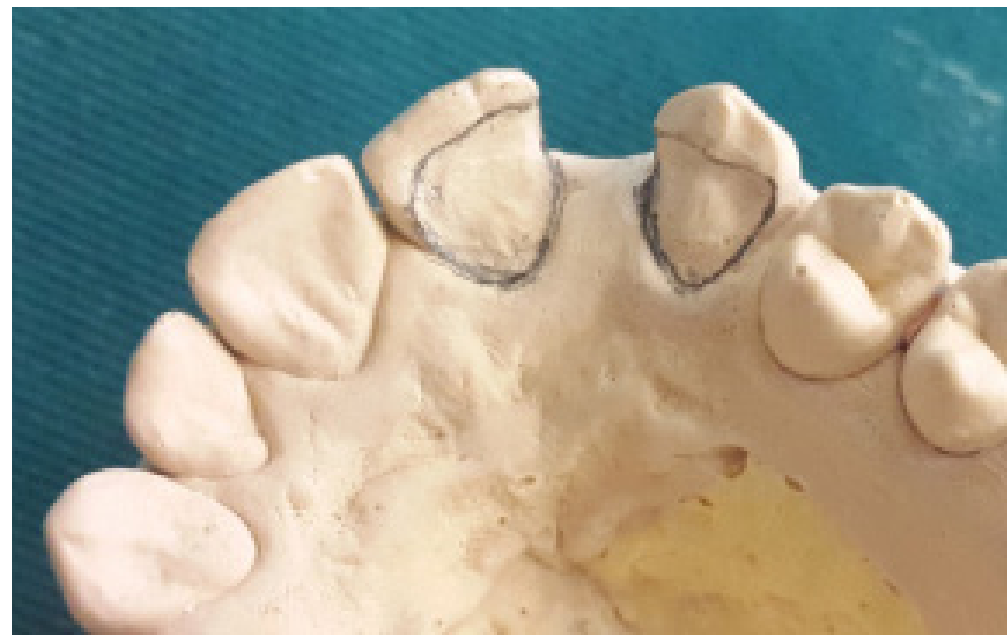

Figure 4: Marking preparation area on the cast

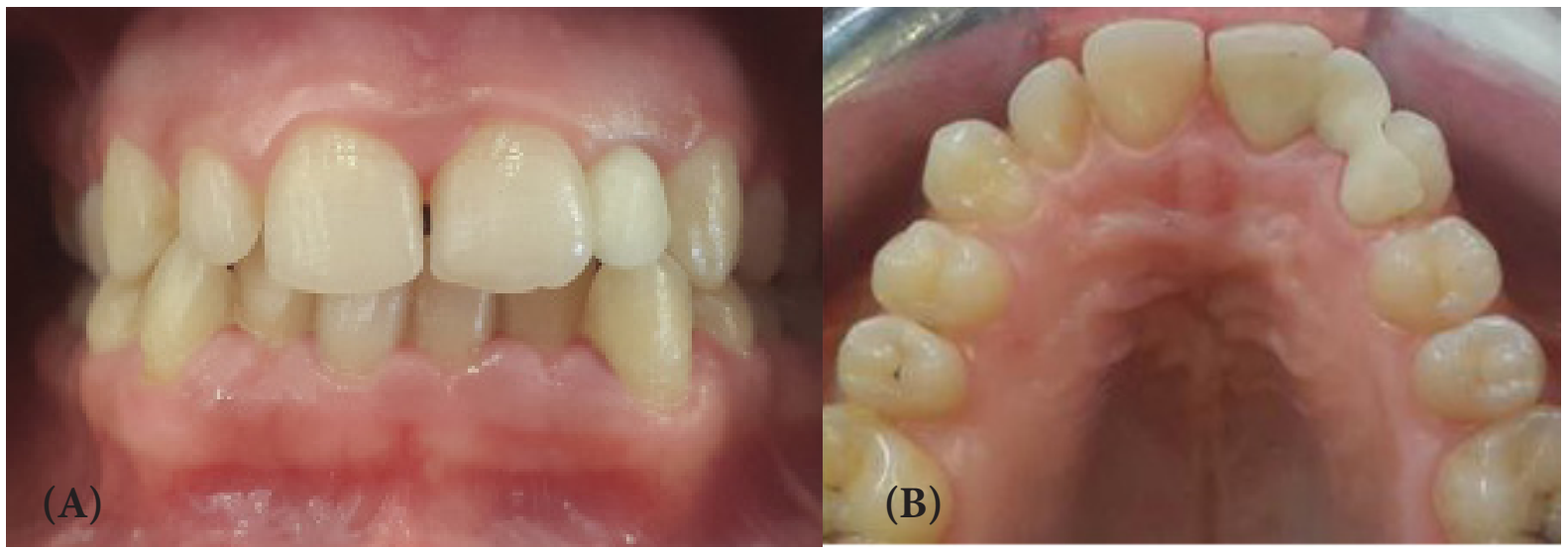

Figure 5: Provisional restoration. A: frontal view, B: lingual view 
At the initial trial insertion, complete seating of the prosthesis, marginal adaptation of each retainer, tissue contact, stability, form of the substructure for the pontic, and occlusion were assessed. Subsequently, the premature contacts were eliminated, and the shade of the pontic was determined and recorded (Figure 6 and 7). In a second step, external layers of feldspathic veneering porcelain were fired onto the frameworks, matching the characteristics of the adjacent natural teeth. After that, a second trial evaluation session was conducted. All characteristics described previously were reviewed, and final agreement from the patient was obtained.

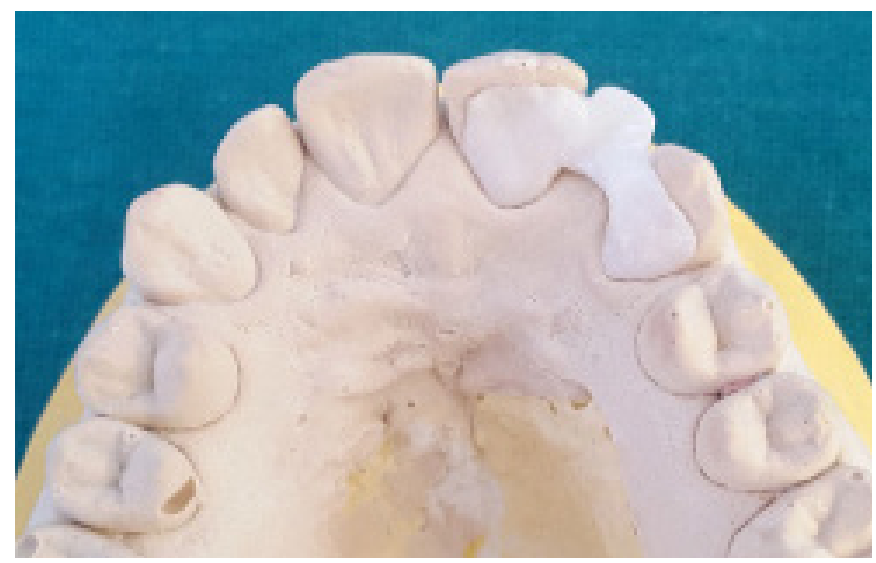

Figure 6: Zirconia framework on the master cast

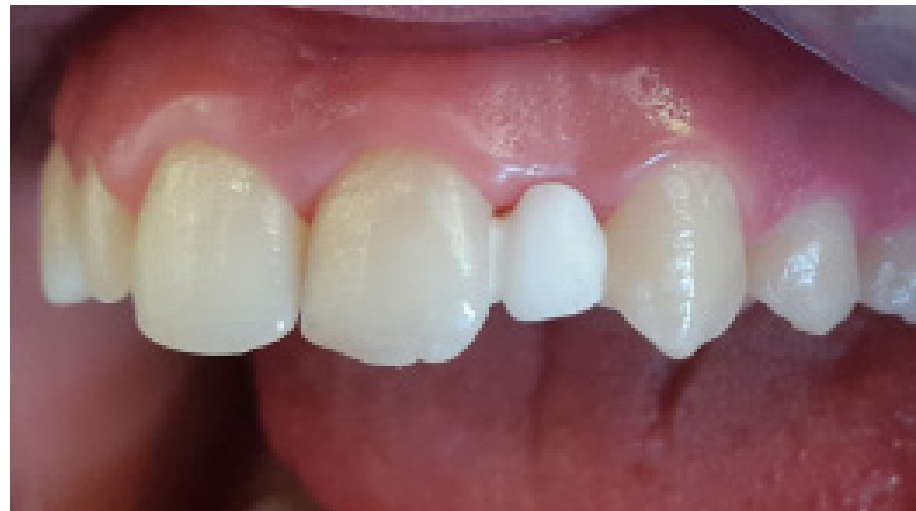

Figure 7: Anterior view of the zirconia framework

The bonding surfaces of the retainer wings were airborne-particle abraded with $30 \mu \mathrm{m}$ aluminum oxide particles at a pressure of 1.5 bar for 5 seconds at a distance of $1 \mathrm{~cm}$. Care was taken to protect the feldspathic veneering porcelain during this procedure. Finally, the abutment areas were isolated and prepared for final cementation. Abutment teeth were cleaned, etched with phosphoric acid (37\%) for $30 \mathrm{sec}$ then rinsed. The Bridge was bonded using a dual polymerizing resin (Rely X $\left.{ }^{\mathrm{TM}} \mathrm{U} 100\right)$ (Figure 8). Follow-up was performed every 6 months during the period of one year until now in order to evaluate the $\mathrm{ZrO}_{2}$ ceramic RBFPD with regard to function, fracture and esthectis.

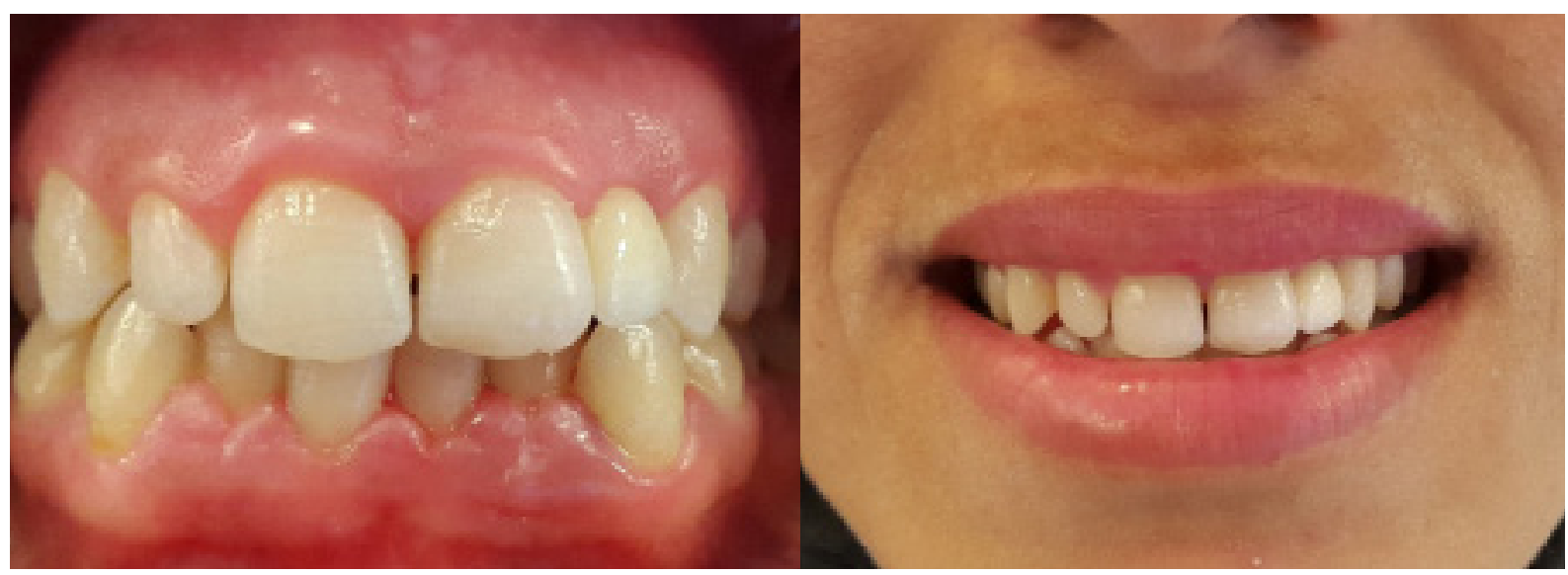

Figure 8: Final result after 6 months 


\section{Discussion}

Resin-bonded fixed partial denture can be used with success to replace missing teeth, mainly if the patient presents vital and noncarious abutments and a minimal occlusal contact on the retainer and the pontic. The advantages of replacing missing teeth with RBFPDs are its noninvasive approach to dentin with lingual and proximal tooth preparation, esthetic appearance because they keep the natural texture of buccal faces and tissue tolerance because of supragingival margins. In addition, they offer low costs, no risk of pulp irritation and low risk of caries since no unnoticed loss of retention will occur [10]. An all-ceramic RBFPD has an advantage over a metal-ceramic one in esthetics and biocompatibility. Both glass-ceramic and high-strength oxide ceramic can be used to produce optical properties similar to those observed in natural tooth [11].

This clinical report describes a treatment option for the replacement of a missing lateral incisor using two-retainer RBFPD fabricated from $\mathrm{ZrO}_{2}$ ceramic. The follow-up demonstrated excellent esthetics and the stability of the $\mathrm{ZrO}_{2}$ ceramic RBFPD was satisfactory. The patient was also satisfied with the outcome.

The choice of two retainers was justified by the increase of the area of preparation and thus the bonding performance. In fact, this provides a large surface area of enamel to aid in bonding the framework to the abutment teeth. Furthermore, some studies revealed a significantly higher fracture resistance for two-retainer RBFPDs than for cantilever RBFPDs [12].

The use of a zirconia based ceramic was proved for its excellent mechanical properties. One of the main causes for failure of allceramic is the fracture of the connector area. The fracture strenght of the connector depends not only on the dimensions of the connector, but also on the mechanical properties of the materials used. $\mathrm{ZrO}_{2}$ ceramic, as employed for the framework of RBFPD in this case, has superior physical properties to aluminium oxide $\mathrm{Al}_{2} \mathrm{O}_{3}$ ceramic [4]. Besides, using this material and thanks to its strength properties, the proximal connector size can be reduced. It was estimated about 2.6 times smaller than the connector size made from $\mathrm{Al}_{2} \mathrm{O}_{3}$ ceramic [13]. The long term result of $\mathrm{ZrO}_{2}$ ceramic RBFPD is therefore supposed to be more predictable than the $\mathrm{Al}_{2} \mathrm{O}_{3}$ ceramic $\mathrm{RBFPD}$. In fact, the clinical outcome of RBFPDs made from zirconia ceramic has been studied in a randomized controlled clinical trial showing a 5-year complication-free rate of $93.3 \%$ [14].

A common cause of failure of RBFPD is the debonding. In fact, Goodacre, et al. showed that the debonding rate varies between $10 \%$ and $24 \%$. Moreover, the debonding rate for RBFPDs with more than 1 pontic (52\%) was doubles that the framework supporting a single pontic [15]. In the present case, the RBFPD supported a single pontic. As zirconia cannot be acid-etched, long-term resin bond strength can be achieved through the use of either silica-silane coating or air-particle abrasion with aluminum oxide and a ceramic bonding system containing special adhesive phosphate monomers. In this case, the inner retainer surfaces were airparticle abraded.

Finally, to minimize eventual risk of debonding or failure of the restoration, the RBFPD should be checked in maximum intercuspation (MIP) and dynamic excursions. The retainer should be in light contact in MIP even if the tooth was not in occlusion prior to RBFPD placement. The pontic should also be in light contact in maximum intercuspation but any contact in excursions eliminated [16].

\section{Conclusion}

Although implant-supported prostheses are ultimately the best solution for patients with congenitally missing incisors, some cases do not allow its realization. Zirconia based all ceramic resin bonded fixed partial denture seems to be a suitable treatment modality. This restoration may satisfy the functional and esthetic demands of today's patients. It is a minimally invasive and very conservative treatment approach, cost effective and requiring few treatment steps. However, certain clinical guidelines and laboratory steps have to be followed closely, and controlled clinical trials are necessary to verify the long-term success of RBFPD.

\section{References}

1. Kokich VO, Kinzer GA (2005) Managing congenitally missing lateral incisors. Part I: canine substitution. J Esthet Restor Dent 17: 5-10.

2. Mayer TM, Hawley CE, Gunsolley JC, Feldman S (2002) The single-tooth implant: a viable alternative for single-tooth replacement. J Periodontol 73: 687-93.

3. Rubinstein S, Nidetz AJ, Hoshi M (2004) A Multidisciplinary Approach to Single-Tooth Replacement. QDT 27: 1-19.

4. Tanoue N, Nagano K, Sawase T, Matsumura H (2010) A nine-year clinical case study of a resin- bonded fixed partial denture seated on the maxillary anterior teeth. J Prosthodont Res 54: 143-6.

5. Ketabi AR, Kaus T, Herdach F, Groten M, Axmann-Krcmar D, et al. (2004) Thirteen-year follow-up study of resin bonded fixed partial dentures. Quintessence Int 35: 407-10.

6. Pjetursson BE, Tan WC, Tan K, Brägger U, Zwahlen M, et al. (2008) A systematic review of the survival and complication rates of resin-bonded bridges after an observation period of at least 5 years. Clin Oral Implants Res 19: 131-41.

7. Pilathadka S, Vahalova D (2007) Contemporary all-ceramic materials, part-1. Acta Medica 50: 101-4.

8. Nemoto R, Nozaki K, Fukui Y, Yamashita K, Miura H (2013) Effect of framework design on the surface strain of zirconia fixed partial Dentures. Dent Mater J 32: $289-95$.

9. Rosentritt M, Kolbeck C, Ries S, Gross M, Behr M, et al. (2008) Zirconia resin-bonded fixed partial dentures in the anterior maxilla. Quintessence Int 39: 313-9. 
10. Turker SB, Guvenli SY, Arikan A (2005) Replacement of two mandibular central incisors using a zirconium resin-bonded fixed partial denture: a clinical report. J Prosthet Dent 94: 499-503.

11. Kara HB, Aykent F (2012) Single tooth replacement using a ceramic resin bonded fixed partial denture: A case report. Eur J Dent 6: 101-4.

12. Rosentritt M, Ries S, Kolbeck C, Westphal M, Richter EJ, et al. (2009) Fracture characteristics of anterior resin-bonded zirconia-fixed partial dentures. Clin Oral Investig 13: 453-7.

13. Sasse M, Kern M (2014) All ceramic resin resin bonded fixed dental prostheses treatment planning, clinical procedures, and outcome. Quintessence Int 45: 291-7.

14. Sasse M, Kern M (2013) CAD/CAM single retainer zirconia-ceramic resin-bonded fixed dental prostheses: clinical outcome after 5 years. Int J Comput Dent 16: $109-18$.

15. Goodacre CJ, Bernal G, Rungcharassaeng K, Kan JY (2003) Clinical complications in fixed prosthodontics. J Prosthet Dent 90: $31-41$.

16. Lally U (2013) Resin-bonded fixed partial dentures past and present - an overview. J Ir Dent Assoc 58: 294-300.

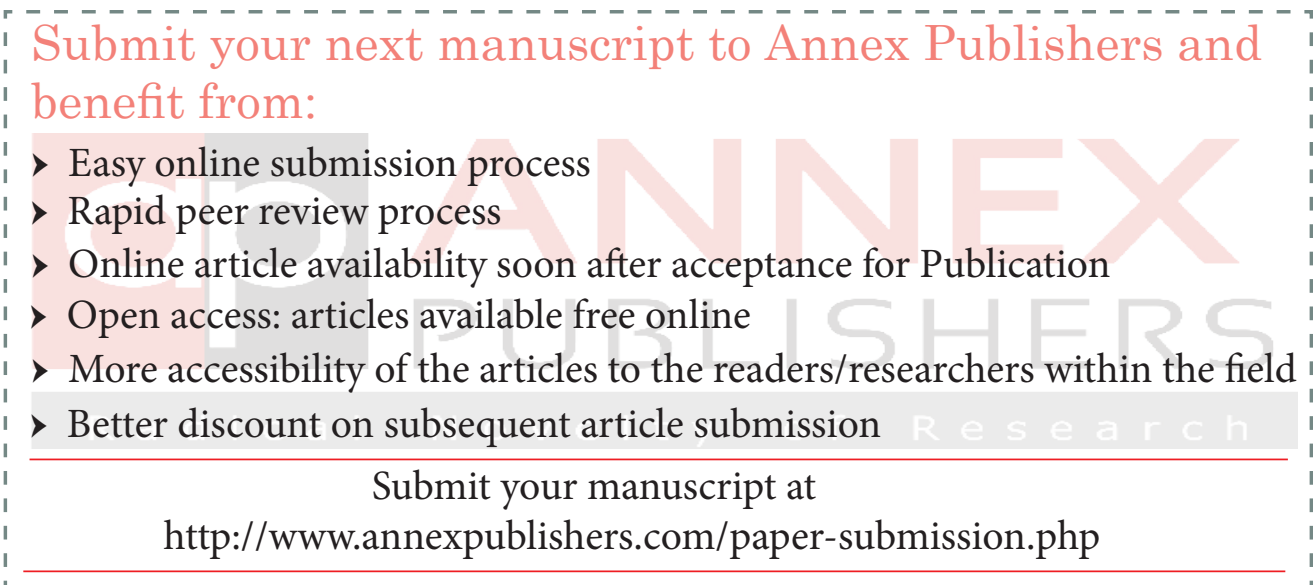

